The Journal of Laryngology \& Otology

http://journals.cambridge.org/JLO

Additional services for The Journal of Laryngology \& Otology:

Email alerts: Click here

Subscriptions: Click here

Commercial reprints: Click here

Terms of use : $\underline{\text { Click here }}$

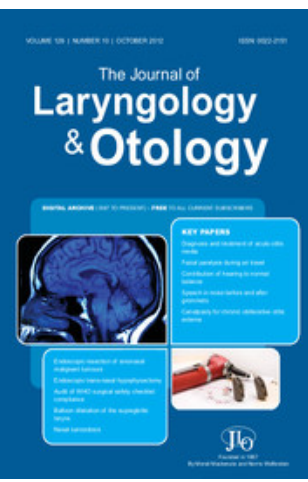

\title{
Photodynamic therapy of malignant and premalignant lesions in patients with 'field cancerization' of the oral cavity
}

W. E. Grant, C. Hopper, P. M. Speight, A. J. Macrobert and S. G. Bown

The Journal of Laryngology \& Otology / Volume 107 / Issue 12 / December 1993, pp 1140 - 1145

DOI: 10.1017/S0022215100125496, Published online: 29 June 2007

Link to this article: http://journals.cambridge.org/abstract_S0022215100125496

How to cite this article:

W. E. Grant, C. Hopper, P. M. Speight, A. J. Macrobert and S. G. Bown (1993). Photodynamic therapy of malignant and premalignant lesions in patients with 'field cancerization' of the oral cavity. The Journal of Laryngology \& Otology, 107, pp 1140-1145 doi:10.1017/S0022215100125496

Request Permissions : $\underline{\text { Click here }}$ 


\title{
Photodynamic therapy of malignant and premalignant lesions in patients with 'field cancerization' of the oral cavity
}

\author{
W. E. Grant, F.R.C.S.I.*, C. Hopper, F.R.C.S. (Ed), F.D.S.R.C.S.†, P. M. SPEIGHT, M.R.C. Path. $\ddagger$, \\ A. J. Macrobert, Ph.D.*, S. G. Bown, M.D., F.R.C.P.* (London)
}

\begin{abstract}
The management of patients with 'field cancerization' of the oral mucosa, with multicentric foci of invasion, presents a considerable problem for the head and neck surgeon. Surgical resection of synchronous or metachronous primary squamous cell carcinomas, along with adjacent premalignant lesions, is likely to be associated with considerable mutilation. Photodynamic therapy (PDT) has been shown to be of value in the treatment of superficial tumours in the upper aerodigestive tract, with excellent healing of treated areas. This study reports the use of PDT to treat 11 patients with 'field cancerization' occurring in the oral cavity. Six patients had multiple primary cancers and five had single primary tumours. All had associated areas of leukoplakia. Each received Photofrin $2 \mathrm{mg} / \mathrm{kg} 48$ hours prior to photoirradiation with $50-100 \mathrm{~J} / \mathrm{cm}^{2}$ red laser light by surface illumination. Six to eight weeks later treated areas in 10 of the 11 patients showed a complete response to PDT; one patient had areas of residual leukoplakia. Two patients developed further areas of leukoplakia or erythroplakia within 12 months but no patient has had evidence of recurrent invasive carcinoma in the treated areas. Longer term follow-up will be necessary to exclude further recurrence. It is concluded that PDT offers an effective repeatable treatment option, whether on its own or as an adjunct to local excision, for patients with 'field cancerization' of the oral cavity.
\end{abstract}

Key words: Photodynamic therapy; Head and neck neoplasms

\section{Introduction}

The coexistence of premalignant lesions such as leukoplakia and erythroplakia with an existing primary lesion greatly increases the chance of developing a second primary cancer (Sarasin, 1933; Wilkins and Vogler, 1957; Moertal and Foss, 1958; Shibuya et al., 1986). Leukoplakia, a term describing a white patch or plaque that cannot be characterized clinically or pathologically as any other disease entity (Kramer et al., 1978), has a definite propensity for malignant transformation. This is variously estimated as being between 0.13 and 17.5 per cent (Pindborg et al., 1968; Silverman et al., 1976; Silverman et al., 1984). The presence of an erythematous component, erythroplakia, or erythroleukoplakia increases almost fourfold the risk of malignant transformation (Silverman et al., 1984). The incidence of multiple oral carcinomas in patients with primary tongue carcinomas associated with leukoplakia has been found to be five times greater than that of subjects without leukoplakia (Shibuya et al., 1986). The prognosis of patients who develop synchronous or metachronous second primary cancers is poor with overall five-year survival ranging from nine to 22 per cent (Marchetta et al., 1965; Gluckman and Crissman, 1983). Slaughter et al. (1953) first proposed the concept of 'field cancerization' to explain the multicentric origin of squamous cell carcinoma arising in a given anatomical region, exposed to the same carcinogenic agents. The diagnosis of a second primary tumour in the same anatomical site, or the coexistence of premalignant lesions such as leukoplakia or erythroplakia, suggests that the entire mucosa is at risk of malignant change. Satisfactory treatment for patients with such a wide field change should ideally be non-mutilating and repeatable.

Photodynamic therapy (PDT), in which exogenous photosensitizing drugs are administered to render tumour tissue sensitive to nonthermal light, is beginning to be recognized as an effective therapeutic modality (Pass, 1993). Early clinical experience shows that PDT is effective in the treatment of superficial lesions, particularly such clinical entities as urothelial bladder cancers, early bronchogenic carcinomas and dermatological tumours (Hayata et al., 1984; Benson, 1988; Carruth, 1990; Edell and Cortese, 1990; Pope and Bown, 1991a). A mixed experience has been reported in the treatment of head and neck cancers; reasons for initial failures include inappropriate patient selection, or failure to expose deep extensions of the tumour to adequate light (Gluckman, 1991a). The patient with a wide field change in the oral cavity presents a difficult management problem. Screening of these patients results in detection of areas of invasion while still at an early stage. The ability of PDT to ablate superficial tumours, while at the same time minimizing 
TABLE I

\begin{tabular}{|c|c|c|c|c|c|}
\hline Patient & Tumour site & $\begin{array}{l}\text { Associated } \\
\text { premalignant disease }\end{array}$ & $\begin{array}{l}\text { Appearance of treated } \\
\text { areas at } 6-8 \text { weeks }\end{array}$ & Follow-up & Comments \\
\hline \multicolumn{6}{|c|}{ Primary cancer with associated premalignant disease } \\
\hline 11 & $\mathrm{R}$ bucco-gingival sulcus & $\mathrm{R}$ and $\mathrm{L}$ buccal mucosa & CR, Normal* & 10 months & HIV positive \\
\hline 2 & $\mathrm{R}$ lateral tongue & $\begin{array}{l}\mathrm{R} \text { tongue base, } \mathrm{L} \text { buccal } \\
\text { mucosa }\end{array}$ & CR, Normal & 8 months & $\begin{array}{l}\text { Leukoplakia at } 6 \text { months: mild } \\
\text { dysplasia }\end{array}$ \\
\hline 3 & L buccal mucosa & $\mathrm{L}$ buccal mucosa -3 sites & CR, Non-healing ulcer & 9 months & $\begin{array}{l}\text { Ulcer excised at } 3 \text { months: } \\
\text { inflammatory }\end{array}$ \\
\hline 4 & Tongue (excised) & $\mathrm{L}$ and $\mathrm{R}$ buccal mucosa & CR, Normal & 3 months & \\
\hline 5 & L bucco-gingival sulcus & L buccal mucosa & $\begin{array}{l}\text { CR, Persistence of } \\
\text { OSF }\end{array}$ & 19 months & $\begin{array}{l}\text { Erythroplasia } 1 \text { year - moderate } \\
\text { dyplasia. OSF }\end{array}$ \\
\hline \multicolumn{6}{|c|}{ Multiple primary with associated premalignant disease } \\
\hline 6 & L buccal mucosa -2 sites & L buccal mucosa - 2 sites & CR, Normal & 9 months & \\
\hline 7 & $\mathrm{R}$ alveolar ridge & $\begin{array}{l}\mathrm{R} \text { buccal mucosa, floor of } \\
\text { mouth }\end{array}$ & CR, Normal* & 10 months & Metachronous primary 8 months \\
\hline 8 & $\mathrm{~L}$ alveolar ridge & $\mathrm{R}$ buccal mucosa and alveolus & CR, Normal & 7 months & \\
\hline 9 & Tongue tip & Dorsum and lateral tongue & IR, Some leukoplakia & 18 months & Biopsied: moderate dysplasia \\
\hline 10 & Palate/Lbuccal/R alveolus & $\mathrm{R}$ tongue and buccal mucosa & CR, Normal* & 6 months & Metachronous primary 3 months \\
\hline 11 & Lip & Lip & CR, Normal & 18 months & \\
\hline
\end{tabular}

$\mathrm{CR}=$ Complete response: no evidence of abnormal mucosa, either histologically or clinically, at time of assessment; IR = incomplete response: residual premalignant lesion in treated area; OSF $=$ oral submucous fibrosis. ${ }^{*}=$ Biopsied: histologically normal mucosa.

loss of normal tissue suggests that it should be ideally suited to the treatment of this disease. This study reports clinical experience with photodynamic therapy using Photofrin (Lederle Laboratories) in the treatment of superficial early carcinomas, with coexisting premalignant lesions and areas of carcinoma in situ, occurring in the oral cavity.

\section{Materials and methods}

Eleven patients with one or more histologically proven early invasive squamous cell carcinomas of the oral cavity, occurring in association with widespread premalignant disease such as leukoplakia, erythroplakia or 'erythroleukoplakia', were included in the study group. Six patients had synchronous or metachronous second primary carcinomas, and five had a first primary lesion, occurring in association with one or more non-contiguous areas of leukoplakia of more than $5 \mathrm{~mm}$ in diameter (see Table I).

All tumours were diagnosed as Stage $\mathrm{I}\left(\mathrm{T}_{1} \mathrm{~N}_{0} \mathrm{M}_{0}\right)$ oral cancers and no deep extension to underlying muscle or bone was suggested by the clinical, histological or radiological findings. Six patients had had previous oral tumours surgically excised, five on more than one occasion, and now presented with independent second primary carcinomas. One patient had previous $\mathrm{CO}_{2}$ laser excision of dysplastic areas of leukoplakia. Four patients had no prior treatment but had histologically proven squamous cell carcinomas associated with one or more non-contiguous areas of leukoplakia. One patient underwent a combination of surgical resection of a T1 lesion of the tongue and PDT to extensive areas of leukoplakia in both buccal regions. No patient had received radiotherapy. Informed consent was obtained in each case.

Photofrin at a dose of $2 \mathrm{mg} / \mathrm{kg}$ was given by intravenous infusion 48 hours prior to surface illumination of the tumour and all clinically apparent areas of leukoplakia or erythroplakia. A copper vapour pumped dye laser was used to deliver monochromatic red light at $630 \mathrm{~nm}$. An optical fibre with a microlens affixed ensured homogeneity of the illuminating light spot, and a multijointed articulated arm was used to facilitate positioning of the fibre in three planes. Two patients were treated for very extensive disease on two separate occasions. Ten patients required more than one spot to treat the target areas. A light dose of $50-100 \mathrm{~J} / \mathrm{cm}^{2}$ was delivered to each area. Power densities were kept below $150 \mathrm{~mW} / \mathrm{cm}^{2}$ to avoid any possibility of thermal injury, and no patient reported any sensation of heat, although some described various sensations such as tingling and tickling during light exposure. Patients were counselled to avoid direct sunlight for six weeks following sensitization, and this advice was reinforced by the provision of a patient advice sheet. Patients were then prescribed analgesics and benzydamine local analgesic/anti-inflammatory spray.

Lesions were photographed and treatment areas were recorded diagrammatically on referral. Following treatment patients were reviewed and photographed twice in the week after PDT and then approximately weekly until healed, and thereafter every two to four weeks. Where treated areas healed with, or subsequently developed, evidence of recurrence of ulceration, erythroplasia or leukoplakia, these lesions were conventionally excised or biopsied to determine the nature of the abnormality and the presence or otherwise of premalignant or malignant recurrence. Three patients had biopsies of regenerated clinically normal mucosa, at sites where invasive carcinoma had been previously diagnosed. Each was taken at times longer than three months following PDT.

Initial response to treatment was evaluated at between six and eight weeks. All cases were then followed-up for periods of three to 19 months to determine whether any early relapse occurred.

\section{Results}

All treatments were performed without local anaesthetic or sedation and were satisfactorily tolerated by each patient, on an out-patient basis. During the three to four days after PDT the treated areas underwent obvious surface necrosis with the development of a superficial slough, and local oedema. While no pain was associated with the treatment itself, all patients developed some degree of 

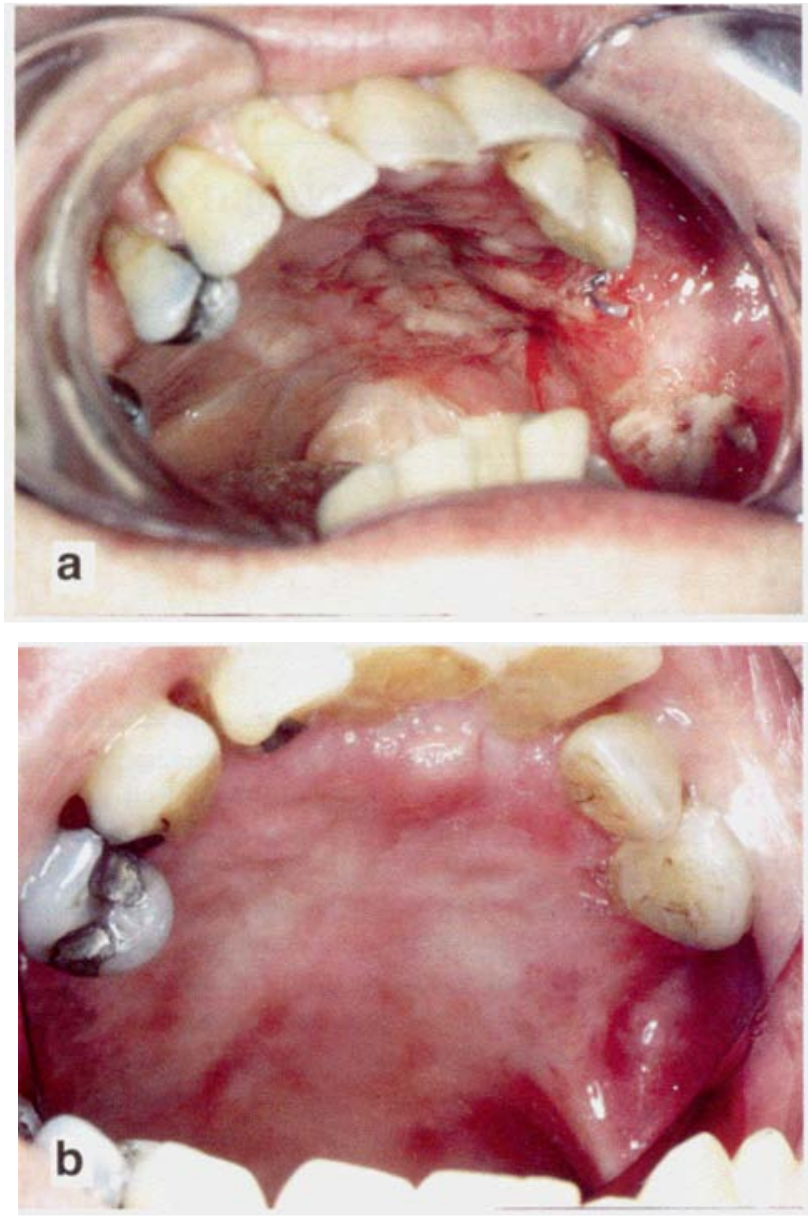

FIG. 1

Photomicrographs of patient 10: before, (a) showing invasive squamous cell carcinoma of the left hard palate and buccal mucosa; and (b), 3 months after PDT showing appearance of palate following healing.

pain over the following days, usually lasting about one week, but this was effectively relieved by oral analgesia. Eating tended to exacerbate pain and a sloppy diet was advised and found to help. Treated areas took between three and five weeks to heal fully, depending on the size of area treated.

At assessment following healing six to eight weeks after PDT, 10 of the 11 patients showed a complete response to treatment. In eight the healed mucosa was of normal colour with no evidence of leukoplakia or erythroplakia (Figure 1a and b). Five patients who had had multiple surgical resections (patients six to ten; Table I), showed evidence of scarring related to previous surgical intervention, but healed with essentially normal mucosa. The three cases in which clinically normal regenerated mucosa was biopsied after three months, showed histologically normal epithelium in two cases (Figure $2 \mathrm{a}$ and b), and an atrophic epithelium without atypia or dysplasia in the third. One patient with pre-existing oral submucous fibrosis healed with scarring, similar in appearance to adjacent untreated mucosa. One patient had a persistent non-healing ulcer associated with dental trauma. This was excised after three months and showed simple ulceration with chronic inflammation.

One patient had an incomplete response, but had almost the entire surface of his tongue treated in two separate treatments. More than 75 per cent healed with regeneration of mucosa of normal colour but with some atrophy, and the persistence of a patchy grey-white lesion on the dorsum, showing histological mild dysplasia, meant that this constituted an incomplete response (Figure $3 a$ and $b$ ).

Follow-up to date ranges from three to 19 months, with a mean of 11 months. No patient has developed any evidence of recurrence of invasive squamous cell carcinoma in the treated sites. One patient developed a small area of leukoplakia at the treatment site at six months. This was excised and histology showed hyperkeratosis with moderate epithelial dyplasia. The patient with oral submucous fibrosis developed further erythroplakia at one year which when excised also revealed moderate epithelial dysplasia. Two patients developed further metachronous primary carcinomas at sites away from the treated areas, while maintaining a complete response in the treated area. These were treated with excision and radiotherapy. The remaining seven patients have had no evidence of recurrent carcinoma or further premalignant disease.

\section{Discussion}

The complete response of 10 of the 11 patients treated in this study demonstrates the efficacy of PDT in ablation of early invasive and premalignant lesions in the oral cavity. The finding that in most cases the abnormal epithelium healed with regeneration of essentially normal mucosa indicates that early superficial carcinomas and associated dysplastic lesions can be effectively destroyed in situ with minimal tissue loss using PDT. The two cases that devel-
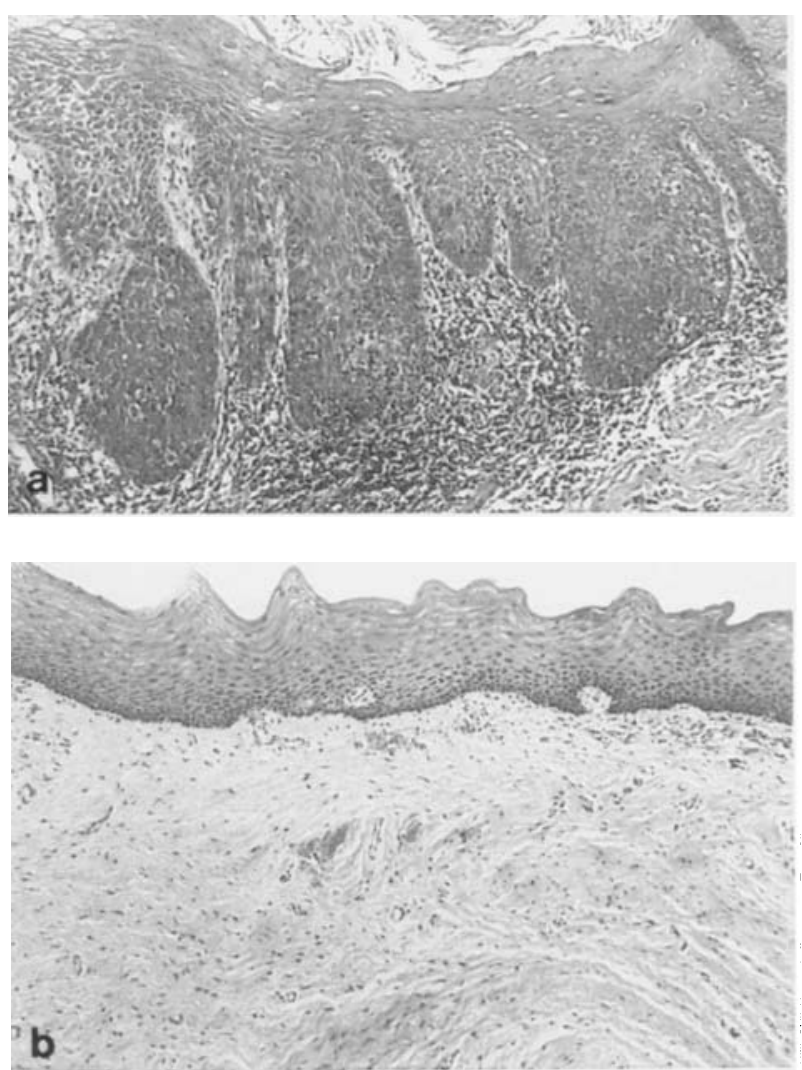

FIG. 2

Photomicrographs of histological sections showing: (a) early invasive carcinoma of the right lower bucco-gingival sulcus before PDT: and (b) showing appearance following healing with normal mucosa. 

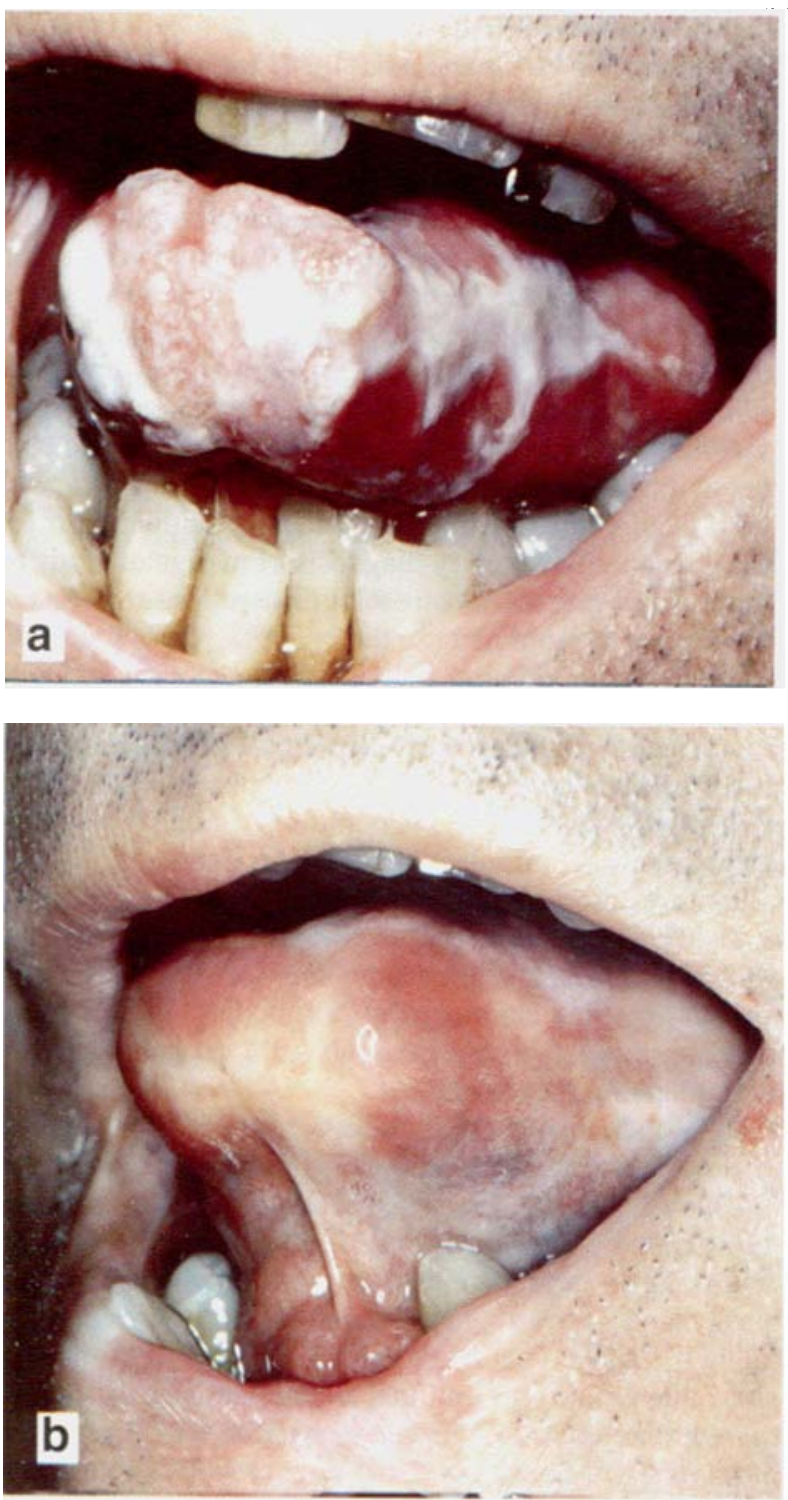

FIG. 3

Photomicrographs of patient 9: before (a) and after (b) PDT for extensive 'field cancerization' of the tongue. Patient had multiple prior surgical resections of tongue and lower lip. Appearance at 16 months following PDT.

oped recurrent areas of dysplasia at six months and one year respectively were disappointing but given the nature of their field change not unexpected. Both patients subsequently had these lesions excised, but further PDT would certainly be a treatment option in the future. The development of metachronous primary cancers in two patients is also not unexpected and again reflects the field change nature of the disease rather than any influence of PDT, as the sites were not related.

The incidence of second or multiple cancers arising in the upper aerodigestive tract has been variously reported as being from seven to 30 per cent (de Vries, 1990). The presence of more than one primary carcinoma has a profound influence on survival, and therefore management. Cohn and Peppard (1980) found that 75 per cent of patients who developed second primary tumours in the upper aerodigestive tract died within 12 months of the second diagnosis. Gluckman and Crissman (1983) found that overall five-year survival after diagnoisis of a second primary was 22.3 per cent (compared with 35 per cent for a control group with single lesions). Carr and Langdon (1989) found that the average survival of patients with index oral cancers who developed second primaries was seven months. Two-thirds of this series died less than six months after diagnosis of the second tumour. Close follow-up screening of all patients with a diagnosis of upper aerodigestive tract carcinoma is necessary to facilitate early detection of a second primary and recurrent disease. Similarly patients with leukoplakia showing histological evidence of dysplasia, but without frank invasion, require close follow-up. Both these situations present the opportunity for the histological diagnosis of carcinoma at a stage when deep invasion has not yet taken place, and when the lesion may be amenable to either further resection, or less mutilating interventional techniques, such as PDT.

Management of areas of dysplastic oral mucosa is a considerable problem because of multiple sites, often diffuse margins and variable and unpredictable risk of malignant transformation. Similarly management of an isolated primary tumour by surgical resection with safe oncological margins, and effective reconstruction where necessary, may in itself also pose considerable difficulty. When leukoplakia occurs in conjunction with one or more primary tumours, indicating the likelihood of a wide field change, these difficulties are greatly compounded.

Therapeutic options for patients with extensive 'field cancerization' will depend on several factors, including the timing of presentation of the tumours, whether simultaneous or metachronous, the site and stage of the lesions, and the age and general health of individual patients. Concern has frequently been expressed about the possibility of radiotherapy converting premalignant disease into anaplastic and frankly invasive carcinoma, and the long-term effect of radiation on the regional field mucosa remains unclear. Normal oral mucosa exposed to ionizing radiation during the treatment of orofacial tumours displays abnormal DNA profiles, which although returning to normal within six weeks, retains the potential for latent radiation damage (Ogden et al., 1989). Children and adolescents exposed to irradiation show a predisposition to neoplasia in the head and neck (Martin et al., 1970; Southwick, 1977; De Groot et al., 1983). Robinson et al., 1991 report decreased mean survival times for patients with second primary head and neck cancers where index tumours received radiotherapy over patients who had surgery alone. For simultaneous primary cancers surgical resection may be feasible if two or more primary lesions are in close geographical proximity, but may offer the prospect of extensive reconstruction with unacceptable loss of function and cosmesis if occurring at different sites. For metachronous lesions curative surgery is undertaken on the merits of the individual case, but the problems of function and cosmesis are the same. Other approaches to the management of premalignant lesions of the oral cavity include the use of retinoids, but the improvements in oral leukoplakia produced by treatment with vitamin A related compounds have not all been sustained and, more seriously, toxicity has been an accompaniment of some treatments (Scully and Boyle, 1992).

Photodynamic therapy has been shown to be effective in vitro, and in vivo for the ablation of small areas of malignant disease. Selective photodynamic destruction of 
tumour without injury to normal tissue has not been possible using currently available photosensitizing drugs. However the ability of surrounding normal tissues to heal satisfactorily by regeneration, coupled with the selective illumination of target areas results in ultimate selectivity of tumour destruction. Normal tissues in the oral cavity, notably mucosa, muscle and salivary gland have been shown, in studies in rats, to heal or regenerate well following PDT using a sulphonated phthalocyanine sensitiser. Bone appeared to be resistant to photodynamic injury (Meyer et al., 1991). Further studies in rats show that PDT-treated stomach, colon and bladder healed largely by regeneration with normal tissue (Barr et al., 1987; Pope and Bown, 1991b; Loh et al., 1992). Clinical studies demonstrate excellent healing of skin and mucosal surfaces following PDT with Photofrin (Gilson et al., 1988; Barr et al., 1990). Photodynamic therapy offers the potential for minimal tissue loss with preservation of function. The present study confirms these observations in the oral cavity, and demonstrates that diffuse areas of superficial malignancy and premalignant disease can heal with clinically or histologically normal mucosa following treatment.

Early clinical reports of PDT in the head and neck comprise feasibility studies in patients with advanced disease, and demonstrate variable tumour response and palliation. Visible light penetration is maximal in the red region of the spectrum, but is not capable of causing necrosis of more than a few millimetres from the surface so that surface illumination of bulky tumours is likely to be of little value. More recently it has been recognized that PDT is more appropriate for the treatment of superficial lesions. Wenig et al. (1990) used PDT to treat 26 patients with early stage head and neck cancer who refused conventional treatment or failed previous treatment of surgery, radiotherapy, chemotherapy or combination therapy. These authors used an 'idealized' mathematical light dosimetry model to match light delivery to magnetic resonance imaging of tumour volume. Complete responses were reported in 20 ( 77 per cent) and partial responses in five (19 per cent) as assessed at three months. Nine of these patients had oral cavity tumours. Unfortunately there appears to be a wide variation in the optical properties of individual tumours and few conform to idealized geometries (Grant et al., 1992). Gluckman (1991b) treated 13 early ( $\mathrm{T} 1$ and $\mathrm{T} 2$ ) carcinomas of the oral cavity and oropharynx by surface irradiation. He obtained complete response in 11 ( 84 per cent) at 1 month, with the remaining two being partial responses. However, of these 11 , four recurred between eight and 12 months. He concedes that this high late recurrence rate may have been due to a variety of factors and expresses concern about the possibility of deep tumour being left untreated. The same author, in the only other study to address 'field cancerization' patients, reports results in eight patients with condemned mucosa (defined as biopsy proven multicentric premalignant and overtly malignant lesions). He obtained excellent results in seven patients in the short term. A number developed recurrent leukoplakia on long-term follow-up but only one was 'positive' on biopsy. Seven out of eight patients with condemned mucosa had a complete response at follow-up from six to 53 months. He found that results achieved in aiming to palliate eight patients with advanced cancer were disappointing and in fact skin photosensitivity may have worsened their quality of life and therefore he abandoned PDT for this indication. These and other experiences with PDT both in the head and neck and in other sites have contributed to the growing body of opinion that PDT should be confined to the treatment of early superficial malignancies only.

The principle shortcomings of PDT using Photofrin are essentially twofold: first the failure of light to penetrate deeper than a few millimetres beneath the surface, or from the light source in the case of interstitially implanted fibres, and secondly the prolonged retention of photosensitizing drugs by the skin resulting in protracted cutaneous photosensitization. In the management of a wide field change disease, regular clinical examination offers the opportunity for early diagnosis of malignant transformation. If representative histological sections confirm that the lesion is confined to the mucosa, then successful photodynamic ablation is likely. The second problem is that of cutaneous photosensitization, with drugs such as Photofrin, making protracted periods of avoidance of direct sunlight a necessity. This problem is likely to be eliminated with the next generation of photosensitizing agents, such as aminolaevulinic acid (Grant et al., 1993), which are more rapidly cleared from the skin. Furthermore improved selectivity may become possible with new photosensitisers, and the conjugation of such drugs with tumour specific monoclonal antibodies may further improve this situation, although little progress has yet been made in this direction.

This study demonstrates the efficacy of PDT in ablation of early invasive and premalignant lesions in the oral cavity. A viable therapeutic alternative to extensive mutilating surgery may thus be offered. While long-term follow-up is necessary to determine recurrence of premalignant and overtly malignant foci, and this is certainly likely by the very nature of the disease, it must be emphasized that unlike conventional techniques such as surgery or radiotherapy, PDT may be repeated without loss of normal tissue. Irreversible side effects such as those seen in salivary, bony and vascular tissues with radiotherapy are also avoided. PDT offers the prospect of effective in situ treatment of both early invasive malignancy and coexistent premalignant disease. Where more advanced malignancy occurs in a background of condemned mucosa, PDT may be considered as an adjunct to local resection, or debulking, of the primary focus.

\section{Conclusion}

Photodynamic therapy offers a welcome therapeutic option in the treatment of multifocal 'field cancerization' of the upper aerodigestive tract. Its use alone, or where indicated, in conjunction with surgical excision, offers functional and cosmetic advantages over conventional treatment modalities for this difficult condition. While long-term follow-up data is still required, repeated treatment with PDT may offer a more acceptable option than multiple surgical resections.

\section{Acknowledgements}

William Grant is supported by the Association for International Cancer Research, and Stephen Bown by the Imperial Cancer Research Fund. We are grateful to 
Dr Giovanni Buonaccorsi and Dr Tim Mills, Department of Medical Physics, University College London, for laser technical support, and to Sister Michelle Vickers for help with patient management. We are grateful to Lederle Laboratories for providing the Photofrin.

\section{References}

Barr, H.. Krasner, N., Boulos, P. B., Chatlani, P., Bown, S. G. (1990) Photodynamic therapy for colorectal cancer: a quantitative pilot study. British Journal of Surgery 77: 93-96.

Barr, H., Tralau, C. J., MacRobert, A. J., Krasner, N., Boulos, P. B., Clark, C. G. Bown, S. G. (1987) Photodynamic therapy in the normal rat colon with phthalocyanine sensitisation. British Journal of Cancer 56: 111-118.

Benson, R. C. (1988) Treatment of bladder cancer with haematoporphyrin derivatives and laser light. Urology 31 (Suppl. 1): 13-17.

Carr, R. J., Langdon, J. D. (1989) Multiple primaries in mouth cancer - the price of success. British Journal of Oral and Maxillofacial Surgery 27: 394-399.

Carruth, J. A. S. (1990) Photodynamic therapy of tumours involving the skin and head and neck. In Phototherapy of Cancer. (Morstyn, G.. Kaye, A.. eds.). Harwood Academic Publishers, London, pp 173-184.

Cohn, A. M., Peppard, S. B. (1980) Multiple primary malignant tumours of the head and neck. American Journal of Otolaringology 1(5): $411-417$.

De Vries, N. (1990) Incidence of mulptiple primary tumours in head and neck cancer. In Multiple Primary Tumours in the Head and Neck. (de Vries, N., Gluckman, J. L., eds.). Georg Thieme Verlag, Stuttgart and New York, pp 4-5.

DeGroot, L. J., Reilly, M., Pinnamenini, K., Refetoff, S. (1983) Retrospective and prospective study of radiation-induced thyroid disease. American Journal of Medicine, 74: 852-862.

Edell, E. S., Cortese, D. A. (1990) Detection and phototherapy of lung cancer. In Phototherapy of Cancer. (Morstyn, G., Kay, A. eds.). Harwood Academic Publishers, London, pp 185-198.

Gilson, D., Ash, D., Feather, J. W., Brown, S. (1988) Therapeutic ratio of photodynamic therapy in the treatment of superficial tumours of skin and subcutaneous tissues in man. British Journal of Cancer 58: 665-667.

Gluckman, J. L., Crissman, J. D. (1983) Survival rates in 548 patients with multiple neoplasms of upper aerodigestive tract. Laryngoscope 93: 71-74.

Gluckman, J. L. (1991 a) Haematoporphyrin photodynamic therapy: is there truly a future in head and neck oncology? Reflections on a five-year experience. Laryngoscope 101: 36-41.

Gluckman, J. L. (1991b) Photodynamic therapy for head and neck neoplasms. Otolaryngologic Clinics of North America 24: 1559-1667.

Grant, W. E., Hopper, C., Speight, P. M., Bown, S. G. (1992) Photodynamic therapy of the oral cavity: response of normal tissues and squamous carcinomas. In Photodynamic Therapy and Biomedical Lasers. (Spinelli, P., Dal Fante, M., Marchesini, R., eds.). Elsevier Scientific Publishers, Amsterdam, pp 638-641.

Grant, W. E., Hopper, C., MacRobert, A. J., Speight, P. M., Bown, S. G. (1993) Photodynamic therapy of oral cancer: photosensitization with systemic aminolaevulinic acid. Lancet 342: 147-148.

Hayata, Y., Kato, H., Konaka, C., Amemiya, R., Ono, J., Ogawa, I. (1984) Photoradiation therapy with haematoporphyrin derivative in early and stage 1 lung cancer. Chest 86: 169-177.

Kramer, I. R. H., Lucas, R. B., Pindborg, J. J., and Sobin, L. H. (1978) Definition of leukoplakia and related lesions: an aid to studies on oral precancer. Oral Surgery, Oral Medicine, Oral Pathology 46: 518-539.

Loh, C. S., Bedwell, J., MacRobert, A. J., Krasner, N., Phillips, D., Bown, S. G. (1992) Photodynamic therapy of the normal rat stomach: a comparative study between di-sulphonated aluminium phthalocyanine and 5-aminolaevulinic acid. British Journal of Cancer 66: 452-462.

Marchetta, F. C., Sako, K., Camp, F. (1965) Multiple malignancies in patients with head and neck cancer. American Journal of Surgery 110: $537-541$.

Martin, H., Strong, E., and Spiro, R. H. (1970) Radiation-induced skin cancer of the head and neck. Cancer 25: 61-71.

Meyer, M., Speight, P., Bown, S. G. (1991) A study of the effects of photodynamic therapy on the normal tissues of the rabbit jaw. British Journal of Cancer 64: 1093-1097.

Moertal, C. G., Foss, E. L. (1958) Multicentric carcinomas of the oral cavity. Surgery; Gynecology and Obstetrics 106: 652-654.

Ogden, G. R., Cowpe, J. G., Green, M. W. (1989) Effect of radiotherapy on oral mucosa assessed by quantitiative exfoliative cytology. Journal of Clinical Pathology 42: 940-943.

Pass, H. I. (1993) Photodynamic therapy in oncology: mechanisms and clinical use. Journal of National Cancer Institute 85(6): 443-456.

Pindborg, J. J., Jolst, O., Renstrup, G., Roed-Petersen, B. (1968) Studies in oral leukoplakia: a preliminary report on the period prevalence of malignant transformation in leukoplakia based on a follow-up study of 248 patients. Journal of the American Dental Association 78: 767-771.

Pope, A. J., Bown, S. G. (1991a) Photodynamic therapy. British Journal of Urology 68: 1-9.

Pope, A. J., Bown, S. G. (1991b) The morphological and functional changes in the rat bladder following photodynamic therapy with phthalocyanine photosensitisation. Journal of Urology 145: $1064-1070$.

Robinson, E., Neugut, A. I., Murray, Rennert, G. (1991) A comparison of the clinical characteristics of first and second primary head and neck cancers. A population based study. Cancer 68: 189-192.

Sarasin, R. (1933) Les manifestations successives des epitheliomes des muqueuses de la cavité buccale; sont-elles des recidives uraies ou resultent-elles des recidives uraies ou resultent-elles de nouvelles cancerisations? Radiophysique et Radiotherapie 3: 33-76.

Scully, C., Boyle, P. (1992) Vitamin A related compounds in the chemoprevention of potentially malignant oral lesions and carcinoma. Oral Oncology, European Journal of Cancer 2 (28b): $87-89$.

Shibuya, H., Amagasa, T., Seto, K., Ishibashi, K., Horiuchi, J., Suzuki, S. (1986) Leukoplakia-associated multiple carcinomas in patients with tongue carcinoma. Cancer 57: 843-846.

Silverman, S., Bhargava, R., Mani, N. J., Smith, L. W., Malaowalla, A. M. (1976) Malignant transformation and natural history of oral leukoplakia in 57,718 industrial workers in Gujarat, India. Cancer 38: $1790-1795$.

Silverman, S., Gorsky, M., Lozada, F. (1984) Oral leukoplakia and malignant transformation. Cancer 53: 563-568.

Slaughter, D. P., Southwick, H. W., Smejkal, W. (1953) 'Field cancerisation' in oral stratified squamous epithelium. Cancer 6: 963-968

Southwick, H. W. (1977) Radiation-associated head and neck tumours. American Journal of Surgery 134: 438-443.

Wenig, B. L., Kurtzman, D. M., Grossweiner, L. I., Mafee, M. F., Harris, D. M., Lobraico, R. V., Prycz, R. A., Appelbaum, E. L. (1990) Photodynamic therapy in the treatment of squamous cell carcinoma of the head and neck. Archives of Otolaryngology, Head and Neck Surgery 116: 1267-1270.

Wilkins, S. A., Vogler, W. R. (1957) Cancer of the gingiva. Surgery, Gynecology and Obstetrics 105: 145-152.

Address for correspondence:

William E. Grant, F.R.C.S.I.

Department of Otolaryngology

Royal Free Hospital,

Pond Street,

London NW3 $20 \mathrm{OG}$ 